\title{
Development of the model of the Virtual Test Platform of the Chassis Hydraulic System of the Tacked Vehicle Based on AMESim
}

\author{
Xiaonan Zhao ${ }^{1}$, Qinghui Xiong ${ }^{2}$, Lidong $\mathrm{Gu}^{1}$, Linsen Song ${ }^{1}$ \\ ${ }^{1}$ College of Mechanics and Electronic, Changchun University of Science and Technology \\ Changchun, 130022, China \\ ${ }^{2}$ China Vehicle Research Institute, Beijing, 10072, China \\ email:gulidong1112@126.com
}

Keywords: AMESim, hydraulic system, virtual test platform

\begin{abstract}
By analyzing the working principle of the chassis hydraulic system of a certain tracked vehicle, a simulation model of the virtual hydraulic test platform has been built. The model is not only used to simulate the pressure and the flow rate of the hydraulic system in the environment of the virtual test platform, but also used to invocate models and optimize the state parameters. According to simulating some parts, the detailed model can be replaced with the functional models and the computation can be greatly reduced by replacing.
\end{abstract}

\section{Introduction}

The control model of the hydraulic system of a certain tracked vehicle is using the quantitative pumps and relief values. The mechanical power of the oil pump comes from the motor and the transmission system. The flow and the pressure output vary according with the different work environment and condition. Therefore, the simulation model of the virtual test platform of the hydraulic system has been built to simulate and optimize the design and improve the performance and reliability of the system.

\section{Working Principle of the System}

The input power comes from the engine of the vehicle, and the oil pressure and flow of the function subsystems are controlled by high-low pressure oil pumps, constant pressure values and pipe accessories which provide the hydraulic power and lubrication for the key functional subsystems of the chassis, including high pressure braking system, steering system, shifting mechanism, cooling fan drive, transmission lubrication and hydraulic torque converter, etc.

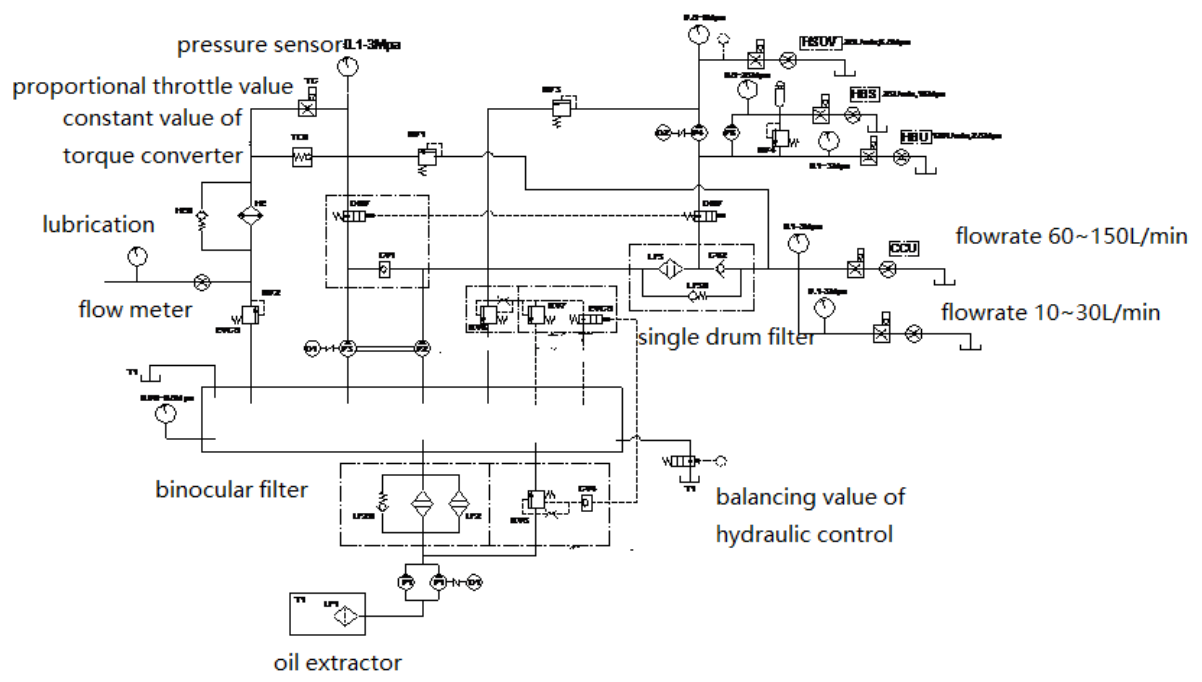

Figure 1 the working principle of the virtual test platform 
In order to simulate the flow demand of each function subsystem, the cylinder, damping air and proportional value are adapted on the test platform to simulate the real load and boundary condition which is consistent to the physical hydraulic test platform. Thus the simulation result can be verified by the experimental. The working principle of the test platform is presented as the figure $1^{[1-4]}$.

\section{Development on the Simulation Model}

\section{Constant pressure value}

(1)Model Building of the Constant Pressure Value

The $\operatorname{RV} x(x=1,2,3 \ldots)$ presented in the figure 1 are constant values, used to limit the maximal pressure of the each branch. The characteristic of the constant value depending on the design parameters on mechanics, significantly influences the functional properties of the system. The constant values used in the model are built by the hydraulic component design (HCD) of the AMESim on the basis of the real CAD structure. For instance, the RV2 model presented in the figure 2 has been built with the structure size of the spool and seat of the value, the mechanical stiffness and preload of the constant pressure spring.

(2) Independent Simulation of the Constant Pressure Value

Defining the inlet pressure as increment of 0-10 bar within 10 seconds, the characteristics of the constant pressure, including the opening characteristic, the flow rate and pressure gradient, the saturation point and characteristic have been independently computed. The simulation result has been presented in the figure 3.

(3)Replacing the Detailed Model with the Functional Model

The functional model of the constant pressure value selected from the hydraulic of the AMESim and whose parameters have been set according to the characteristic of the RV2 can be used instead of the model of the constant value based on the HCD in the main system if the computing result of the functional model can be consistent with the model in HCD.

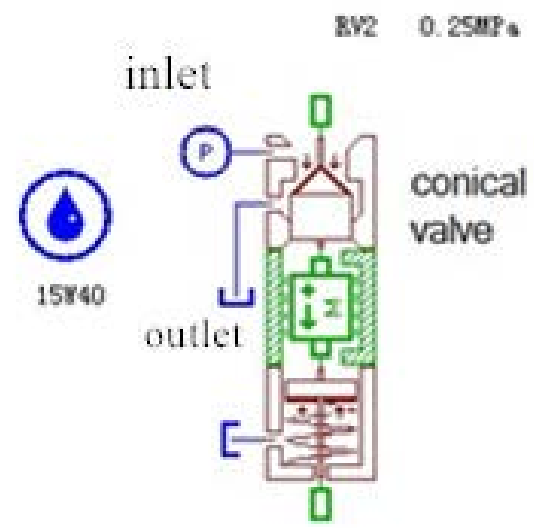

Figure 2 the detailed physical model of RV2

(4) Analysis of Replacement Result

Comparing the functional structure of the RV2 and the simulation result of the hydraulic characteristic of the HCD model, presented in the figure 3, there is only a slight difference in the second-derivative frequency rate of the pressure gradient of the value flow. However, the opening pressure, the saturation point and characteristic can stay consistent.

Therefore, the detailed model can be replaced approximately with the functional structure of the RV2. While ensuring the smaller difference in the simulation result, this can greatly improve the computational efficiency. 


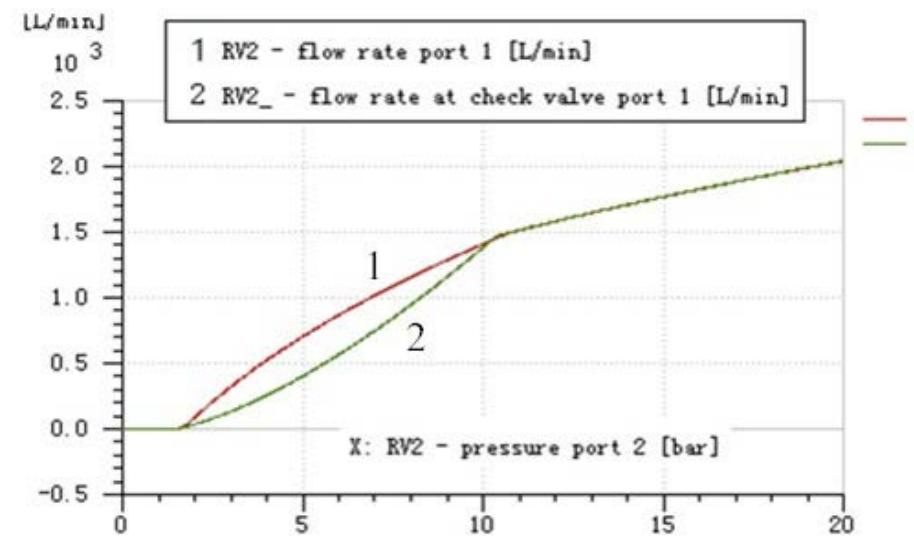

Figure 3 the simulation result of the hydraulic characteristic of RV2

\section{Lubrication Subsystem}

The lubrication subsystem composed by process and local loss components, including pipe, junction, bend, transition and nozzle, is used to lubricate and cool the bearings and components. The Pro/E model of the system is presented as figure 4.

The loss of the partial pressure when oil flows through resistance elements increases with the flow rate. The Q-dp relationship of the over-current components differs from the definition of the resistance coefficient. The hydraulic resistance of the AMESim pools local models whose characteristic of the resistance loss has been defined and covers the accessories such as junction, transition, bend and so on. In addition, the flow resistance coefficient obtained by experience has been presented.

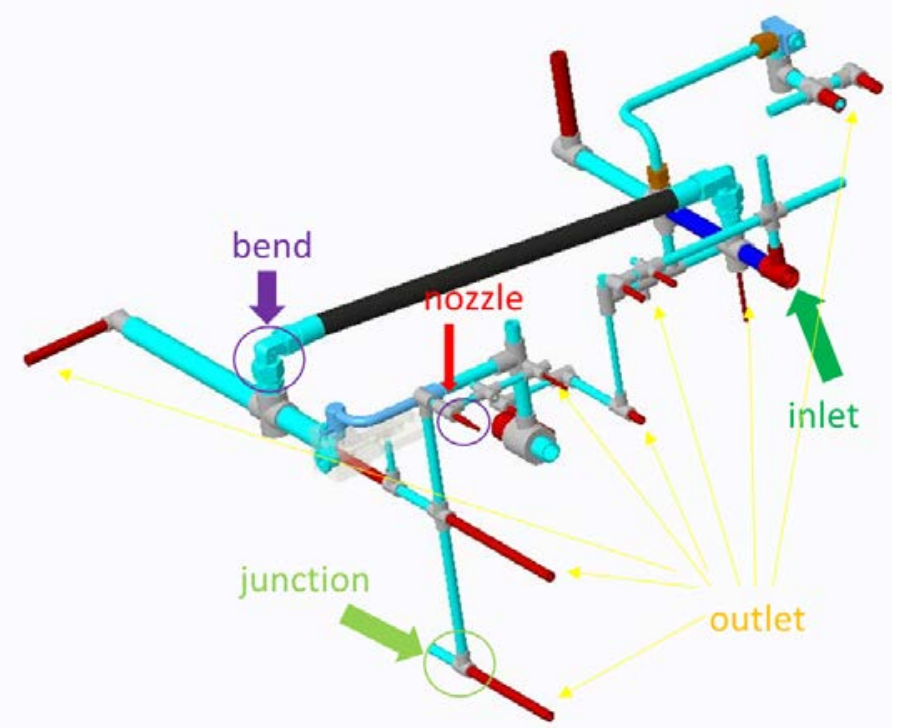

Figure 4 the CAD model of the lubrication system

\section{Model building of the resistance of the pipe network by lumped parameter method}

According to the 3D pipe model, the model of resistance characteristic of the pipe network can be built by lumped parameter method ${ }^{[5]}$. The liquid in the pipe can be defined as a lumped mass, while the resistance due to the accessories can be concentrated on one place. The lumped parameter model of the pipe-network resistance characteristic of the lubrication subsystem has been presented in the figure 5. 


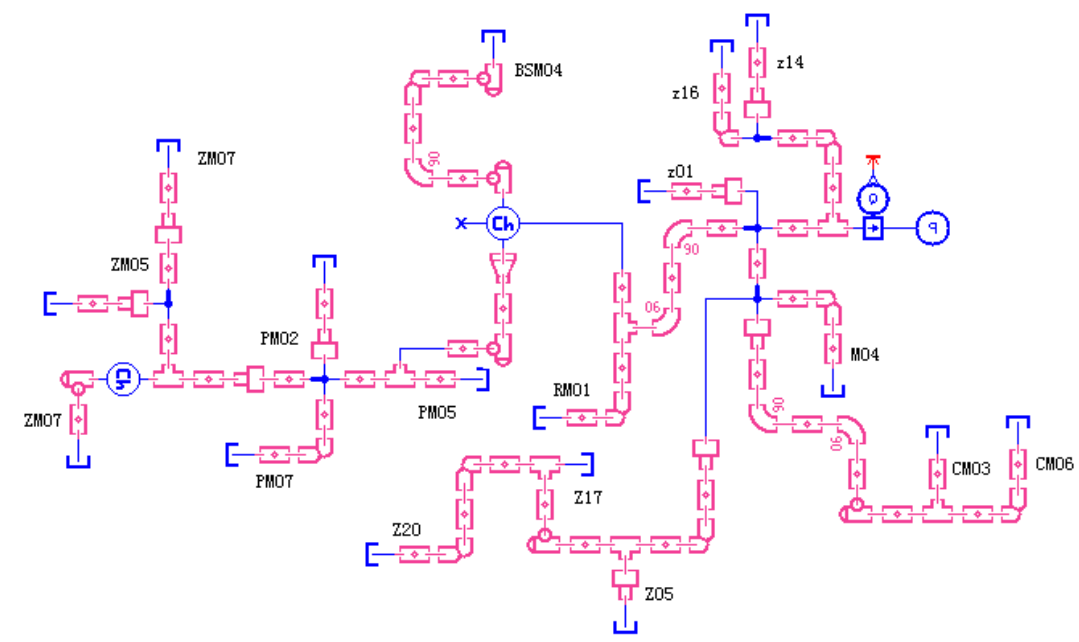

Figure 5 the lumped parameter model of the resistance characteristic of the lubrication system

\section{Replacing Models}

After setting parameter of the inlet pressure and computing the variety of the total flow of the subsystem with the linear increasing 0-2 bar, the resistance characteristic of the lubrication subsystem showed as the Q-dp curve which has been presented as the figure 6 can be obtained.

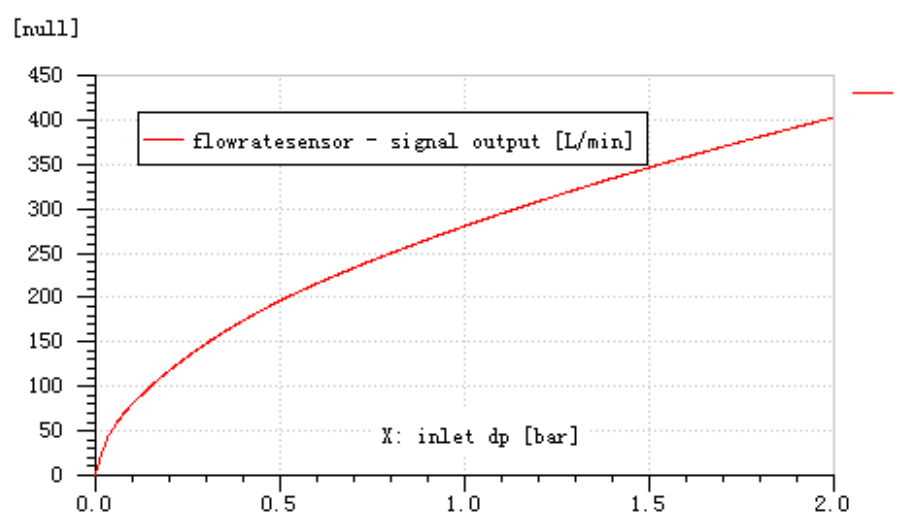

Figure 6 the curve of the resistance characteristic of the lubrication subsystem

Based on the figure 6, the resistance characteristic of the lubrication system can be expressed in saturation point (2bar, $400 \mathrm{~L} / \mathrm{min}$ ). Referencing the model replacing method, the lubrication system can be considered as a flow demand equipment, and the resistance characteristic is equivalent to a damp orifice. By replacing the model, the computation of the main system model has been reduced greatly.

\section{The Model of Main System}

According to the hydraulic principle, the model of the main system has been built. In the model, the practical pipe has been replaced with a fixed chamber. Indeed, it is feasible for steady-state conditions. However, if the focus is on a certain transient process, the model of the pipe should be built in detail. 


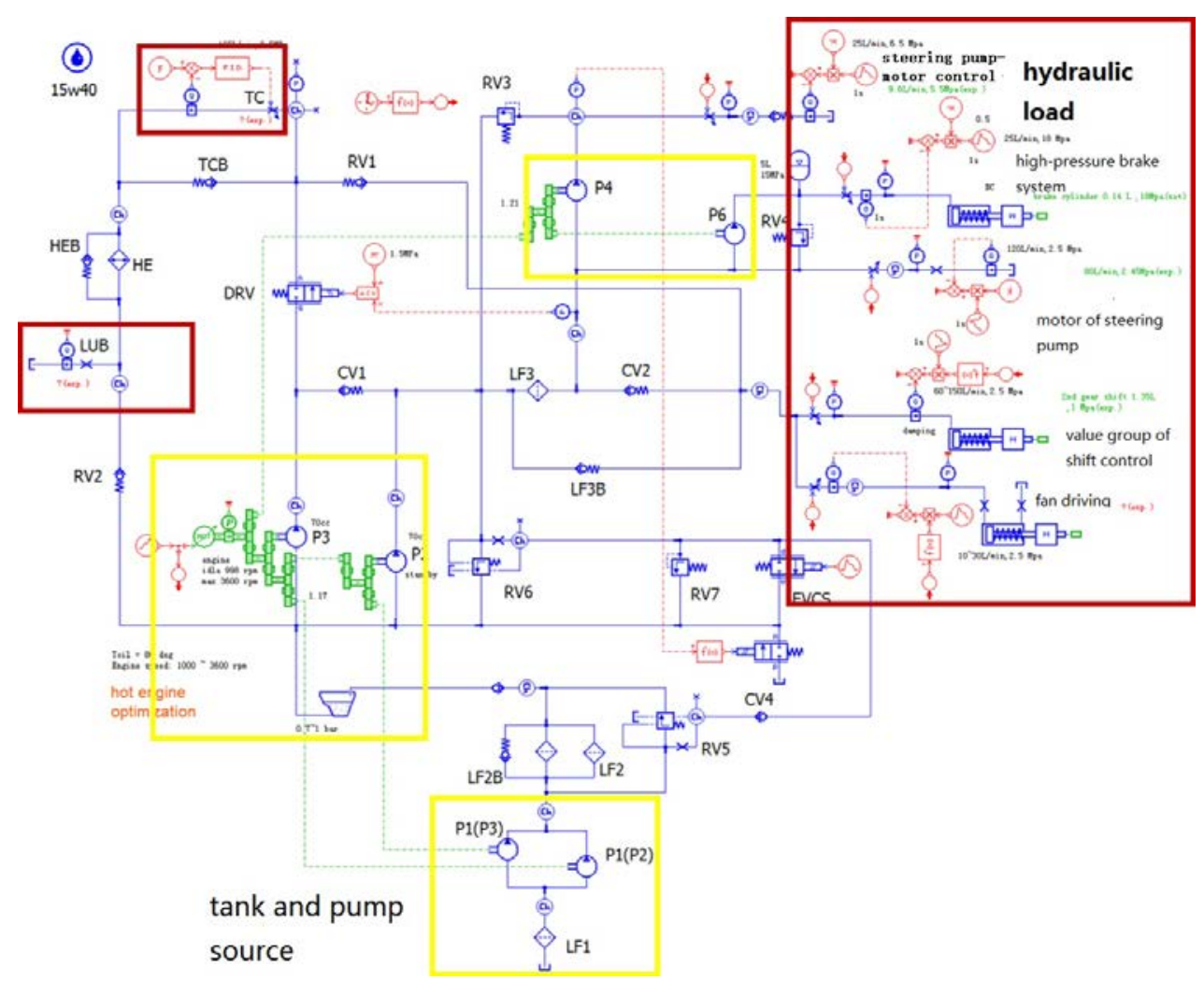

Figure 7 the AMESim model of the hydraulic system

\section{Simulation}

\section{The Definition of the Simulation Condition and the Observables}

The simulation conditions are as follows: running steadily in the heat condition; maximum speed 3600rpm of engine; oil temperature $80^{\circ} \mathrm{C}$ and loading in 0.2 seconds.

The definition of the observable is load flow.

\section{Exactions and Analysis of the Simulation Result}

The curve exacted from the simulation result has been presented as figure 8 , and the variables have been defined in the table 1.

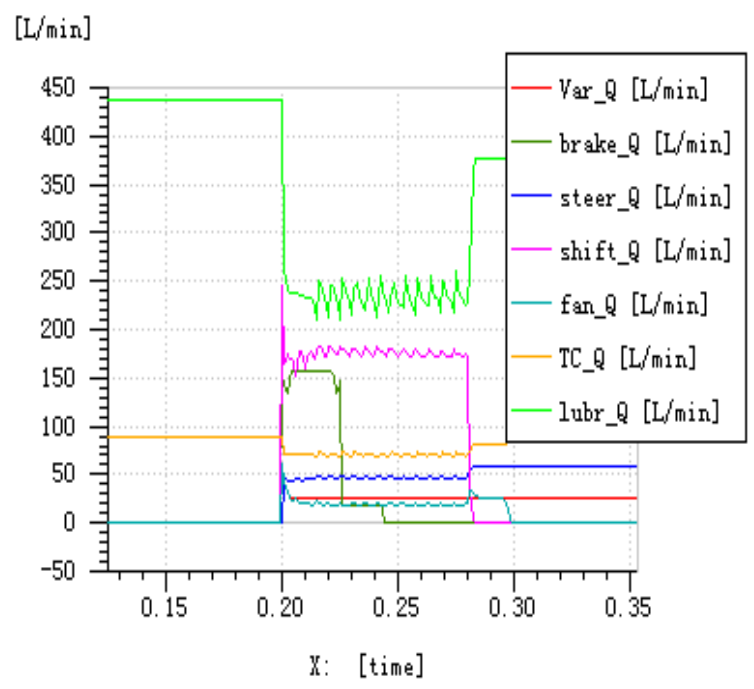

Figure 8 the curves of the simulation result of the loading flow

According to the analysis of the result, the flow demand can reach the steady state with opening of the load in 0.2 minutes. In the other hand, it can probably fluctuate periodically near the steady point. The flow demand will reduce to zero if the partial load such as cylinder strokes fully. 
Table 1 the observation table of the simulation result of the load flow

\begin{tabular}{|c|c|c|c|}
\hline classification & Positions of the sensors & $\begin{array}{c}\text { Names of the } \\
\text { variables }\end{array}$ & $\begin{array}{c}\text { Simulation } \\
\text { results(L/min) }\end{array}$ \\
\hline \multirow{7}{*}{ Flow rate } & $\begin{array}{c}\text { Variable mechanism of } \\
\text { the steering motor }\end{array}$ & Var_Q & 25.4 \\
\cline { 2 - 4 } & High pressure brake & Brake_Q & 156.4 \\
\cline { 2 - 4 } & $\begin{array}{c}\text { Oil supplement of the } \\
\text { steering }\end{array}$ & Steer_Q & 46.1 \\
\cline { 2 - 4 } & Shifting operation & Shift_Q & 178.7 \\
\cline { 2 - 4 } & $\begin{array}{c}\text { Fan drive } \\
\text { Oil supplement of the } \\
\text { torque converter }\end{array}$ & Fan_Q & 18.2 \\
\cline { 2 - 4 } & $\begin{array}{c}\text { Oil supplement of } \\
\text { lubrication }\end{array}$ & Lubr_Q & 70.8 \\
\hline
\end{tabular}

\section{Conclusion}

Based on the AMESim, the chassis hydraulic system of a certain tracked vehicle has been developed and the simulation model of a virtual hydraulic test platform has been built. The model can be used to simulate the flow and pressure output of the system in the variable conditions and to optimize the computing. As the result of the simulation, the partial detailed models replaced with the functional models can greatly reduce the number of state variables of the system and improve the computational efficiency especially to the post optimization computing which needs dozens of sample simulation.

\section{References}

[1] Xiao Daizong. Simulation Technique of AMESim and its Application in Design and Performance Analysis of Hydraulic System[J]. Ship Science and Technology, 2007, 29 ( Supplement): 142-145.

[2]IMAGINE S. A. AMESim 4. 3 User Mannual[M]. France, 2006.

[3] Tang Yi, Wei Xin, Cao Keqiang. The Simulation of Aero Hydraulic System Based on AmeSim[J]. Machine tool and hydraulics, 2007,35(6): 198-200.

[4] Yu Youguan, Gong Guofang, Hu Guoliang. Simulation Technique of AMESim and its Application inHydraulic System[J]. Hydraulics Pneumatics and Seals, 2005(3):28-31.

[5] Jiang Yajun, Hu Junke, Zhao Bin. Analysis of Pressure Beat Vibration of Pump-motor Hydraulic Transmission System[J]. Noise and vibration control, 2013: 936-938. 